\title{
Engaging Nursery Rhymes as Literary Works for Teaching English in EFL Students
}

\author{
Eka Anggia Rini' \\ ekaanggia_r@yahoo.com \\ FKIP Bahasa Inggris University of Lampung
}

\begin{abstract}
This study aimed to review five articles in engaging nursery rhymes toward teaching literary works in EFL students. By doing library research, the researcher found some problems and the solutions in engaging the nursery rhymes for EFL students. Young learner or children mostly became the subject of nursery rhymes study. Later, Najat and Bradley (2014) concluded that nursery rhymes can be applied for adult learners.
\end{abstract}

Keywords: Nursery Rhymes, Literary Works, Teaching English, EFL students

\section{Introduction}

Songs and rhymes for young children have been passed down for generations. They are fun, children love them, and they provide a warm, nurturing experience between parent and child. What we may not be aware of as we recite simple nursery rhymes or sing songs with children is their enormous educational value. "Experts in literacy and child development have discovered that if children know eight nursery rhymes by heart by the time they're four years old, they're usually among the best readers by the time they're eight." (Fox, M: 2001)

Teaching English in EFL students can use some approach, media, and technique by giving some literary works. It can be short story, drama, novel, song, poetry and nursery rhymes. Nursery Rhymes is very entertaining for students who like experimenting with language and imitating new sound. Nursery rhymes might be considered as the tools for making fun teaching and learning process.

\section{Literature Review}

In this library research, the writer will review and explain five articles. They are Harper (2011), Devina (2012), Shweta(2013), and Sayakhan et al (2014), and Santovac (2015). It will be discussed starting from the oldest one.

Harper, L. J. (2011) defines Nursery rhymes as a socially engaging, playful, and developmentally appropriate way for young children to hear, identify, manipulate, and experiment with the sounds of language. Integrating nursery 
rhymes, jingles and chants, and other traditional literature into the early childhood curriculum contributes to a linguistically rich environment in which young children are exposed to the rich vocabulary, syntactic complexity, and decontextualized language contained within the English language. Combining tactile- kinesthetic activities in which language is intentionally explored, manipulated, and experimented within the context of nursery rhymes and literature enhances children's phonological awareness, sensitivity to rhyme and phonemes, and may stimulate phonemic skill development. Phonological awareness is an important precursor in learning to read. This awareness of phonemes fosters a child's ability to hear and blend sounds, encode and decode words, and to spell phonetically. This quantitative study assessed pre-K children's existing EuroAmerican nursery rhyme knowledge and phonological awareness literacy, provided phonological awareness training with an experimental group of children and investigated the effects of explicit nursery rhyme instruction on participants' phonemic skill levels. These data reveal that children exposed to the intervention consisting of explicit Euro-American nursery rhyme instruction significantly outperformed the children in the control group on rhyme awareness and completion statement measures. Results of this research suggest that knowledge of nursery rhymes enhances children's phonological awareness and sensitivity to individual phonemes and rhyme, and stimulates phonemic skill development. Having read this article, the writer focused on mastering phonemic awareness subconsciously by doing some tasks integratedly. The weakness of this article is the writer did not exposure the students by giving some tasks dealing with phonemic awareness. Since he put the activities belong to three aspects (beginning sound awareness, rhyme awareness, and nursery rhyme awareness). At the end of the assessment process, he just focused on authentic assessment or productive skill. In short, the writer good at evaluating and giving the task to the pre$\mathrm{K}$ students to master the phonological awareness integratedly.

Devina's article (2012) consists of the analysis of the effectiveness of vocabulary building through nursery rhymes for K-2 kindergarten students. The research is held in St.Kristoforus Kindergarten School and the participants consist of 21 students. The writer uses qualitative and quantitative research method for the research. The research was conducted inside and outside the classroom. The writer teaches in the class using the nursery rhymes method and 
gives a written test to the students. The interview with the teacher is also conducted. The result of the observation shows that nursery rhymes are not effective in building the vocabulary of the K-2 Kindergarten students. In her article she wants to share and introduce the simple way to learn vocabulary through Nursery Rhymes. Nursery rhymes might be considered as the tools for vocabulary learning. Nursery rhymes are a method that inspires the minds of young learners and involving or introducing them with literacy. The short, simple, and sweet rhymes help children to learn vocabulary, by using the music and movement, nursery rhymes also can improves children's spatial development skills. Through nursery rhymes children will get encouragement from themselves to learn vocabulary and make them active in class. So, hopefully there would be no more sleepy students and bored students at class. She used mixed-method research by doing qualitative, quantitative, and library research. By doing quantitative research, it became standardized to interpret the data qualitatively. She give some conclusions and suggestions to the readers. From the observation that the writer has done before, the writer suggests that it will be good if the local English teachers can start to get to know about nursery rhymes especially the way to deliver it. Local
English teachers nowadays are still unfamiliar and blind with the nursery rhymes. On the other hand, nursery rhymes will be very helpful for the teacher to apply on the daily teaching and learning activities. Even though there are still a disadvantage or weakness occurs in nursery rhymes that can't be avoid. Sometimes there are some words in the text that is hard to explain and not familiar for children, which are the unusual and unpredictable words. But it is a good option for teacher for including the nursery rhymes in the vocabulary teaching and learning activities despite the monotonous learning activities, because nursery rhymes will help the teachers to create enjoyable and playful atmosphere in class, also it is good to give the children opportunities to practice and learn the vocabulary through nursery rhymes, and it will become a new experience for them. Nursery rhymes can stimulate the children to memorize the words or vocabulary easily, without putting too much effort. Nursery rhyme is a simple method for the teacher to make the class lively and enjoyable, and make the inactive students become active in class too. Having read this article, the writer can elaborate and apply the mixedmethod well in the K-2 Kindergarten students. Yet, she did not enclose the examples of Nursery Rhymes. She should also give the readers the words 
(vocabulary) that those students had been mastered by the K-2 Kindergarten students.

Shweta (2013) Nursery rhymes have always proven to be one of the best ways to teach a language to young learners, as they convey a lot to learn, keeping the learner's attention intact. A young learner loves to play with colours, catchy rhyme and gripping music. Nursery rhymes are a perfect combination of all these. With the advent of science and technology, and ever-changing learner's needs, new instructional materials are introduced every day. Though use of Nursery Rhymes as instructional material has reduced considerably, It will always remain one of the best, entertaining, educating sources of language learning. Since she did not put an abstract, she successfully elaborate the explanation of nursery rhymes and provide some benefits for the students. She wrote the article in form of library research. She collected the information completely. Based on the title she tried to give the readers instructional for young language learners. She creates logical opinions about nursery rhymes by seeing the facts in real life.

The gentle tune of Twinkle, Twinkle, Little Star brings back nostalgic feelings even for adults. Nursery Rhymes are often defined as "A short, rhymed poem or tale for children", and are considered as traditional songs for young children in Britain and many other English speaking countries. Though the tradition of nursery rhymes as a primary source for teaching
English language to children began as early as in the seventeenth century, its influence upon English language teaching remains pivotal.

(Shweta : 2013)

She should make the distinction of the theories that she applied on her article. It seems overlapping for the readers when they read this article, because she did not focus on nursery rhymes. She applied another method, technique and approach so that overlapping might be occured in the classroom.

In addition, Sayakhan and Bradley (2014) focused on In this paper, the authors present a rationale and offer suggestions for how nursery rhymes could be used in the EFL classroom as well as how teachers and/or teachers in training might use nursery rhymes to enhance engagement in learning English. First, the authors define nursery rhymes, give a brief history of the origins, discuss the characteristics, make a case for using nursery rhymes with EFL learners, and last, offer practical suggestions for how nursery rhymes might be used in English as a Foreign (EFL) instruction. A list of accessible nursery rhyme resources is shared at the end. There are many categories in folklore, but the ones children often like the most and adults may remember well are nursery rhymes, fairy tales, fables, myths, legends, and folksongs. Each of these genres contributes 
in some way to the language development of children. Nursery rhymes in particular form one of the foundations of children's as well as adults' literary heritage. This pleasure in nursery rhymes translates into developing many reading, writing and oral language skills such as naturally segmenting sounds in spoken words and playing with real and nonsense words. Additionally, young children appreciate the stories and verses for their rhythm, repetition, and rhyme. In this article,the way she explorate the nursey rhymes looked unique, by giving eye and ear catching. It made the article sounds literary thing. The writers distinguish the nursery rhymes from the former one, famous one, and humorous one. This study belongs to library research in taking the data. Despite library research, it make great contribution to the readers that can be one part of teaching English as a Foreign Language (EFL) to adult learners. Since nursery rhymes are such a fundamental part of exploring English and they occur in many other languages and cultures, they are a natural vehicle for engaging learners of English, no matter their language or cultural background. Nursery rhymes can help older learners develop cultural appreciation as well as annenjoyable way to practice with the new language. This form of light verse can assist older students and adults to learn English. This kind of redundancy in language is also what assists older learners of English to access the new language. In addition to the supportive concepts of rhyme, rhythm and song-like attributes nursery rhymes offer young learners, older English language learners can also benefit from these supports. Some nursery rhymes have a long tradition of political meanings, which can make them more interesting for adult learners. This meaningful history may help learners of English language appreciate the value of learning and using nursery rhymes in speaking, reading and writing. It means that nursery rhymes is not only for young learner or children but also adult learner. Besides those strengths, the writer should provide problems or obstacles that might be happened in EFL class so that the solution that they were given will be suitable and beneficial.

Based on Prosic-Santovac (2015:25) the article argues for and develops criteria that can help teachers of young and very young learners select the rhymes suitable for language instructionin terms of their content, accompanying illustrations and language. She also stated that two hundred years later, nursery rhymes are still being used to aid language development, both in acquisition of the mother tongue and second languages. Tongue twiters, riddles, proverbs, lullabies, clapping rhymes, finger rhymes, 
counting-outrhymes, alphabet rhymes, limericks and feature -naming rhymes all fall into the category of nursery rhymes, function as songs as well. They are 'a common "ingredient" of various programs and are often included in students' books used in English language teaching, especially at preschool and early school age' (Prosic-Santovac, 2009a, p. 64). She applied criteria for choosing appropriate rhymes by considering content, relevance, age appropriateness, means for overcoming problems and exploration of values. She emphasizes on accompanying illustrations represent an important part of children's experience of a rhyme, especially when it is in a foreign language, as pictures support understanding and can serve the purpose of scaffolding. An illustration should concern to the human chracters, animal characters, and setting and activities characters engage in. Besides applying appropriate rhymes, illustrations she also focus in language since the main objective of including rhymes in teaching English to young learner is language learning, this aspect of nursery rhymes should be given due attention as well. The criteria for choosing from the linguistic point of view should, therefore, include selecting the rhymes based on the appropriate level of the language used, the language-learning potential the rhymes offer, and their potential for development of activities around the rhyme. It need not be additionally emphasized that the language of the rhymes used in a classroom must not be offensive in any way. The table below will be represented the activities that can be applied in applying nursery rhymes in the classroom.

\begin{tabular}{|c|c|c|}
\hline Oral activities & $\begin{array}{l}\text { Writing } \\
\text { activities }\end{array}$ & $\begin{array}{l}\text { Other related } \\
\text { classroom } \\
\text { activities }\end{array}$ \\
\hline $\begin{array}{l}\text { Singing along } \\
\text { Writing captions } \\
\text { for }\end{array}$ & $\begin{array}{l}\text { illustrations of } \\
\text { the song }\end{array}$ & Drawing \\
\hline $\begin{array}{l}\text { illustrations/post } \\
\text { ers }\end{array}$ & $\begin{array}{l}\text { Singing while } \\
\text { showing }\end{array}$ & $\begin{array}{l}\text { pictures or } \\
\text { puppets }\end{array}$ \\
\hline $\begin{array}{l}\text { Crossword } \\
\text { puzzles with }\end{array}$ & $\begin{array}{l}\text { vocabulary } \\
\text { from the } \\
\text { rhyme }\end{array}$ & $\begin{array}{l}\text { Drawing } \\
\text { cartoons/comi } \\
\text { cs }\end{array}$ \\
\hline $\begin{array}{l}\text { Sorting jumbled } \\
\text { pictures }\end{array}$ & and reciting & $\begin{array}{l}\text { Supplying the } \\
\text { last word in }\end{array}$ \\
\hline Lines & $\begin{array}{l}\text { Creating/solvi } \\
\text { ng vocabulary }\end{array}$ & $\begin{array}{l}\text { jigsaw } \\
\text { puzzles }\end{array}$ \\
\hline $\begin{array}{l}\text { Sorting jumbled } \\
\text { verses and }\end{array}$ & Reciting & $\begin{array}{l}\text { Writing } \\
\text { simple } \\
\text { sentences to }\end{array}$ \\
\hline $\begin{array}{l}\text { describe the } \\
\text { main characters }\end{array}$ & $\begin{array}{l}\text { Making } \\
\text { puppets and } \\
\text { models }\end{array}$ & $\begin{array}{l}\text { Retelling the } \\
\text { content using }\end{array}$ \\
\hline visual prompts & $\begin{array}{l}\text { Composing } \\
\text { new verses for }\end{array}$ & $\begin{array}{l}\text { the rhyme } \\
\text { accompanied } \\
\text { by }\end{array}$ \\
\hline
\end{tabular}

The strength of this article is she can elaborate the literature review of nursery rhymes completely. Yet, the weakness she did not provide a way to teach nursery rhymes for children in modern era. Having seen the title, the readers will think that this article explain about Nursery Rhymes in modern life. Dealing with this issue, this article will find a solution from the weakness of those five articles.

\section{Nursery Rhymes in EFL Students}


Research reveals that there is a link between nursery rhyme knowledge of preschool children and their future success in reading, writing, and spelling. Bradley and Bryant $(1983,1985)$ report that sensitivity to rhyme and alliteration prior to a child's entry to formal schooling plays a causal role in their reading success several years later.

Nursery rhymes can be one part of teaching English as a Foreign Language (EFL) to adult learners. Since nursery rhymes are such a fundamental part of exploring English and they occur in many other languages and cultures, they are a natural vehicle for engaging learners of English, no matter their language or cultural background. Nursery rhymes can help older learners develop cultural appreciation as well as an enjoyable way to practice with the new language. This form of light verse can assist older students and adults to learn English. This kind of redundancy in language is also what assists older learners of English to access the new language. In addition to the supportive concepts of rhyme, rhythm and song-like attributes nursery rhymes offer young learners, older English language learners can also benefit from these supports. Some nursery rhymes have a long tradition of political meanings, which can make them more interesting for adult learners. This meaningful history may help learners of English language appreciate the value of learning and using nursery rhymes in speaking, reading and writing (Sayakhan and Bradley, 2014)

\section{a. Young vs. Adult learners}

Generally, learners can be divided into three categories based on their age, namely young learners, adolescence, and adult learners. Young learners are those whose ages are between 2 and 14 year old, adolescents are those whose are around 12 to 17 year old, while adult are commonly 16 year old and above. From teaching English as foreign language point of view, young learners are those who learn English as a foreign language for the first six or seven year of the formal school system that is usually in the elementary school level. Seeing from their age, they are about 5 until 12 year old.

Age is one of the major factors that should be taken into account in deciding how to teach the learners. It is because learners with different age will have different characteristics. Young learners do not only focus on what is being taught, but they also learn something else at the same time, such as acquiring information from their surroundings. Moreover, young learners may consider seeing, hearing, and touching are as important as the teacher' explanation. They usually respond the activities focusing their life and experience 
well. They can be good speakers of new a language if they have sufficient facilities and enough exposure of the target language. They may learn foreign language better through a game. Young learners love to play and learn best when they enjoy themselves. Adult learners have mature personality, many years of educational training, a developed intelligence, a determination to get what they want, fairly clear aims, and above all strong motivation to make as rapid progress as possible. An adult is no longer constrained by the educational system or parental pressure to learn English, so the problems of dealing with conscripts do not exist. In addition, adult learners can decide about what they want to learn, but young learners cannot and adult learners may learn best by enabling their abstract thinking. Taking into consideration, the different characteristics between young and adult learners, teachers should select strategies of teaching which suit different ages. (Adi, A and Ratminingsih : 2012)

\section{a. The Importance of Nursery Rhymes}

Having Reviewed 5 articles about, they elaborate the importance of Nursey Rhymes as literary works in EFL students:

1. Harper (2011) stated it clear that early knowledge of nursery rhymes helps children to build awareness of sound patterns of language and plays an important role in a child's linguistic and early literacy development. One of the most important skills is phonemic awareness, or the awareness of individual sounds called phonemes that make up spoken words.

2. Devina's research (2012) nursery rhymes can't be considered as an effective method in building vocabulary, but nursery rhymes have a role in improving the vocabulary skills of the children. Nursery rhymes improve the children vocabulary skills in term of pronunciation. Through the repetition of the rhyming words inside nursery rhymes, children develop their pronunciation skills. Therefore, the repetition of sounds or melodies and the repetition of rhymes in each line can help the children develop their English pronunciation skills.

3. Shwetha (2013) simplified the importance of nursery rhymes in a language learning context can be pointed out as phonemic awareness, developing the vocabulary, inductive learning of grammar, and developing auditory skills in language learner. 
4. Sayakhan and Bradley (2014) assert that Listening to and reciting nursery rhymes enhances early reading skills and phonemic awareness which is said to predict a child's reading success. Yet any age EFL learner can benefit from using nursery rhymes to develop or improve English pronunciations, word play, and more. Nursery rhymes can be one part of teaching English as a Foreign Language (EFL) to adult learners. Since nursery rhymes are such a fundamental part of exploring English and they occur in many other languages and cultures, they are a natural vehicle for engaging learners of English, no matter their language or cultural background. Nursery rhymes can help older learners develop cultural appreciation as well as an enjoyable way to practice with the new language.

5. Prosic-Santovac (2015) claimed that nursery rhymes have been used in teaching English to children for a long time and for a variety of reasons, including linguistic, cognitive, affective, and cultural ones. It can be applied in modern era.

\section{Conclusion and Suggestion}

Nursery Rhymes as literary work can be applied in various goals in the EFL classroom setting. It can stimulates phonemic awareness, pronounciation, vocabulary gramar and reading. Engaging this technique at the early age can affect the learners when they become adult learners.

Teacher in EFL class should apply Nursery Rhymes by considering the age, the appropriate nursery rhymes, and the instructional media. They can mix the nursery rhymes with some technique which belongs to digital technique or current technique.

\section{References}

Adi, A \& Ratminingsih (2012). Teaching English Tenses to EFL Learners:

Deductive or Inductive?

International Journal for CrossDisciplinary Subjects in Education (IJCDSE), Special Issue Volume 2 Issue 2, 2012

Bradley, L., \& Bryant, P. (1983).

Categorizing sounds and learning to read: A 419-421.

causal connection. Nature, 301,

Bradley, L., \& Bryant, P. (1985). Rhyme and reason in reading and spelling. Ann Arbor: University of Michigan Press.

Bryant, P., \& Bradley, L. (1985).

Children's reading problems. Oxford: Blackwell. 
Devina (2012). The Effectiveness of Vocabulary Building through Nursery rhymes for $\mathrm{K}-2$ Kindergarten Students. English Department, faculty of Humanities, Bina Nusantara University.

Fox, M. (2001). Reading magic. San

Diego, CA: Harcourt.

Prosic-Santovac, D. (2009a). Home and

School Use of Mother Goose. Belgrade:

Andrejevic Endowment. Retrieved from

http://books.google.bg/books/about /Home_and_School_Use_of_Moth er_Goose.html?id=q rf2CDD7fwsC\&redir_esc=y

Prosic-Santovac, D. (2015). Making the Match : Traditional Nursery Rhymes and
Teaching English to Modern

Children. CLELEjournal, Volume 3, issue 1 ,

2015.

Shwetha, R (2013). Nursery Rhymes as an Effective Instructional Material for Young Language Learners. Language in India www.languageinindia.com ISSN 1930-2940 Vol. 13:6 June 2013.

Sayakhan and Bradley (2014). Nursery Rhymes as a vehicle for Teaching English as a Foreign Language.

International Journal of Literature and Arts. 2014;

2(3): 84-87. Published online June 30, 2014

(http://www.sciencepublishinggrou p.com/j/ijla) doi:

10.11648/j.ijla.20140203.15 